\title{
Design and investigation of cooperative, scaffolded wiki learning activities in an online graduate-level course
}

Kun Huang

Correspondence: k.huang@uky.edu Department of Curriculum \& Instruction, University of Kentucky, 335 Dickey Hall, Lexington, KY 40506, USA

\begin{abstract}
Informed by the literature on community of inquiry, wikis in education, and scaffolding in technology-supported learning environments, this study reports the design, implementation, and investigation of wiki-supported cooperative learning activities in an online graduate-level theories class. The investigation of emerging research questions revealed students' participation patterns in the wiki learning activities, the relationship between their participation and course performance, and the students' experiences with the scaffolding strategies designed to support their cooperative activities. The study offers implications for designing and scaffolding wiki-based cooperative learning.
\end{abstract}

Keywords: Cooperative learning, Online learning, Distance education, Wikis, Scaffolding

\section{Introduction}

Online teachers are faced with the challenge of fostering communities of inquiry in online classes through the development of teaching, cognitive, and social presences (Garrison, Anderson, \& Archer, 2000). The challenge can be intensified for those classes that have a focus on extensive theories and a student group of vastly different prior knowledge and backgrounds. To tackle the challenge, the researcher, who was the instructor of a graduate-level foundational theories online class, designed and implemented cooperative learning experiences using wikis as a pedagogical tool, with the goal of facilitating students' understanding of course materials and preparing them for higher-order, collaborative learning. The design of the wiki-based cooperative learning activities was informed by a survey of the literature on the affordances and constraints of wikis in education, and on the use of scaffolding in technology-supported learning environments. This article begins with a review of the theoretical frameworks, followed by a detailed account on the design of the wiki learning activities. The research questions emerged in the implementation of the learning activities prompted the researcher to investigate and report in this study.

(C) The Author(s). 2019 Open Access This article is distributed under the terms of the Creative Commons Attribution 4.0 International License (http://creativecommons.org/licenses/by/4.0/), which permits unrestricted use, distribution, and reproduction in any medium provided you give appropriate credit to the original author(s) and the source, provide a link to the Creative Commons license, and indicate if changes were made. 


\section{Theoretical frameworks}

\section{Establishing communities of inquiry in online education}

To ensure successful learning, researchers argue that online learners should have equivalent experiences to those in the face-to-face setting (Simonson, Smaldino, \& Zvacek, 2015). With the separation of distance and often time, confounded by a lack of visual cues, online educators have to seek alternative approaches and tools to provide equivalent learning experiences. To this end, Garrison et al. (2000) advanced a Community of Inquiry (CoI) model, which delineates three key aspects of online learning: teaching presence, social presence, and cognitive presence. While the ultimate goal of online learning is to achieve a high cognitive presence, indicated by higher-order cognitive activities such as analysis and synthesis, successful achievement of a high cognitive presence relies heavily on optimal teaching and social presences (Arbaugh et al., 2008; Garrison, Cleveland-Innes, \& Fung, 2010; Huang, Law, \& Lee, 2018). As such, teaching presence, demonstrated in careful design and strategic facilitation of online learning, becomes essential. Not only can teaching presence promote cognitive presence, it can also foster social presence through mindful building of a supportive community where learners develop personal relationships and feel open to share, negotiate, and collaborate. The heightened social presence, in turn, further enhances cognitive presence (Akyol \& Garrison, 2011).

To fully leverage the power of communities of inquiry, online instructors and learners need to aim for optimal teaching, social, and cognitive presences. Learning tasks should be designed to promote purposeful inquiries whereby learners encounter challenges, explore and integrate information, and eventually resolve the challenges (Garrison, 2017). As learners engage in the learning tasks, interact with content materials, and collaborate with peers, critical reflections and discourses need to be planned and facilitated in order to achieve deep and meaningful knowledge construction (Vaughan, Cleveland-Innes, \& Garrison, 2013). Meanwhile, the instructor should foster a culture of open communication, trust, respect, and responsibility in order to build a cohesive class community (Huang, Lee, \& Dugan, 2016). Around the world, researchers and educators have implemented instructional strategies, often supported by emerging technologies, to build and sustain online communities of practice. For example, in Australia, scenario-based simulations were used to engage pharmacy students in reflective inquiries (Hattingh, Robinson, \& Kelly, 2018); in Germany, an online collaboration platform was used to facilitate and streamline students' discussions with peers and the instructor on course lectures (Islam, Flint, Jaecks, \& Cap, 2017); scholars from the Netherland used peer feedback and its triggered dialogues to promote deep learning among online learners (Filius et al., 2018); U.S. scholars reported the use of various questioning strategies and techniques to promote deep dialogues and cognitive presences in online discussions (Hambacher, Ginn, \& Slater, 2018; Sadaf \& Olesova, 2017).

While the CoI framework has provided timely guidance and general principles for online education, there is a shortage in the literature regarding systematic operationalization of $\mathrm{CoI}$ in specific online courses. The issue is further complicated by the challenge to apply the general principles to various content areas, learners, learning outcomes, and education levels that require adaptive strategies and approaches (Morrison, Ross, Morrison, \& Kalman, 
2019). Therefore, it was the intention of this study to operationalize CoI in an online graduate-level foundational theories class in the subject area of instructional design. Particularly, in consideration of the unique learning objectives, learners, and context of the course, the instructor adopted wikis as a pedagogical tool to facilitate the course learning experience. From the perspective of CoI, teaching presence was reflected in the instructor's design and implementation of wiki-supported learning activities, which aimed to promote students' cognitive and social presences. The next section provides a review of wikis as pedagogical tools in online learning.

\section{Wikis as pedagogical tools in online learning}

The rise of Web 2.0 technologies introduced a new paradigm in education by minimizing technical barriers for learners to create and share web-based content (Ge, Law, \& Huang, 2012; Greenhow, Robelia, \& Hughes, 2009). Weblogs, for example, provide convenient platforms for learners to document and share their experiences and reflections; social networking tools such as Twitter provide social spaces for learners to share short messages and interact with others (Hew \& Cheung, 2013). More recently, Massive Open Online Courses (MOOCs) provide open educational resources to the public through platforms that encompass a variety of pedagogical tools (Breslow et al., 2013). Compared with the aforementioned tools, wikis offer unique functionalities that enable multiple authors to collectively edit same pages of web-based content. Generally, wikis have at least three common features across different platforms. First, a user can edit a wiki page by making any revisions to its content. Once saved, the page automatically displays the latest version. Second, wikis usually have history features that track and document which authors made what changes to a page. The history feature also allows the comparison between versions of a document. Third, most wikis also allow users to make comments on a page.

Successful wiki products such as Wikipedia prompted educators to explore its applications to education (Chao \& Lo, 2011; Lau, Lui, \& Chu, 2017; Lin \& Kelsey, 2009). Technically, the affordances of wikis make them ideal tools for online collaborative learning. Their unique features enable learners to work in groups to collaborate on a paper, a project, or other types of assignments. In reviewing peers' contributions, editing collective works, and integrating different perspectives, learners could naturally engage in active knowledge negotiation and construction (Ahlholm, Grunthal, \& Harjunen, 2017; Hsu, Ching, \& Grabowski, 2014), thereby achieving satisfactory social and cognitive presences. However, as contended by Kim (2012), tools "should be defined by how they are used in specific contexts rather than what technological functions they support" (p.21). The actual use of wikis in education is not without issues. In examining wiki usage based on a population of nearly 180,000 wikis in U.S. K-12 schools, Reich, Murnane, and Willett (2012) found that only $1 \%$ wikis were used for collaborative learning, while the majority were for resource sharing among teachers, content delivery by teachers, or individual works by students. Further, more than a third of wikis were used in language-related subject areas (Reich et al., 2012), whereas other subjects see much less use despite wikis' affordances. Taken together, there appears to be a significant gap between the educational affordances of wikis and their actual use in education. 
While a variety of reasons may underlie the challenge in using wikis to support collaborative learning, the literature suggests at least two factors for consideration. First, learners' collaboration in wikis is often lower than expected. In fact, Lin and Kelsey (2009) pointed out that collaborative writing in wikis was an exception, not the norm. Learners' contributions were often characterized as adding new content, sharing information, editing grammar, or formatting, while the actual revision of content was to a much less extent (Cho \& Lim, 2017; Hadjerrouit, 2014). The comment made by a graduate student in Sharp and Whaley's (2018) study might represent many students' hesitation to edit peers' content, "I didn't want to step on any toes by altering someone else's work" (p.89). Reflecting on the low levels of collaboration, Hadjerrouit (2014) suggested that wikis might be better used to support cooperative, brainstorming, rather than collaborative activities.

Another factor regarding wiki usage is the underlying pedagogy. Numerous researchers observed that effective instructional use of wikis is contingent upon sound design and effective facilitation (e.g., Lin \& Kelsey, 2009; Stoddart, Chan, \& Liu, 2016). Researchers proposed various strategies to scaffold wiki learning activities. For example, Jung and Suzuki (2015) suggested the use of a template, heterogeneous grouping, and peer reviews to scaffold collaboration; De Wever, Hamalaninen, Voet, and Gielen (2015) used a collaboration script to maximize sharing and co-editing among students; Cho and Lim (2017) used both individual and group regulative activities to increase collaborative writing; and Stoddart et al. (2016) drew from the literature a framework to guide instructors in facilitating wiki collaboration.

In light of the literature and the context of the course under investigation, this study chose to use wikis to support the part of the course learning experiences that were more cooperative than collaborative in nature. In formulating tool-specific strategies for the unique implementation (Cho \& Lim, 2017), the author referred to the aforementioned strategies, and additionally turned to the literature on scaffolding learning in technology-supported learning environments, which is introduced next.

\section{Scaffolding in technology-supported learning environments}

The concept of scaffolding was rooted in the works of Wood, Bruner, and Ross (1976), who defined scaffolding as the process of enabling a novice to accomplish a task that would otherwise be impossible. Over the years, various scaffolding frameworks have been proposed to facilitate a variety of learning processes and outcomes, such as constructing evidence-based arguments (Belland, Glazewski, \& Richardson, 2008), science inquiries (Quintana et al., 2004), ill-structured problem solving (Ge \& Land, 2004; Ge et al., 2012), and motivation (Belland, Kim, \& Hannafin, 2013).

In technology-supported learning environments such as wikis, learning is often supported with a suite of scaffolding strategies and tools. Scaffolds can be conceptualized along several dimensions. For example, Saye and Brush (2002) distinguished between hard and soft scaffolds. Hard scaffolds offer pre-planned, static supports. For example, the aforementioned template by Jung and Suzuki (2015) is a form of hard scaffolds. Soft scaffolds provide dynamic and situation-specific guidance, often by a teacher or peers. For example, an instructor's monitoring of and feedback to students' wiki contributions can be considered a soft scaffold. Along another dimension, scaffolds can be conceived 
in four key aspects: Who, What, How, and When (Ge et al., 2012). Regarding Who, the providers of scaffolds can be peers, computer systems, or the instructor. Regarding What, scaffolds can be designed to support a variety of cognitive, metacognitive, or motivational processes. How has to do with the way in which scaffolds are provided. Templates, resources, and social discourses are all different scaffolding approaches. Lastly, When is about the timing of scaffolding, which can be pre-designed, just-in-time, or throughout the duration of learning. The different conceptualizations of scaffolding provided helpful guidance in the design of scaffolds for the wiki activities in this study.

Informed by the theoretical frameworks, the researcher took on a design experiment approach (Brown \& Campione, 1996) to design, implement, and investigate cooperative, scaffolded wiki learning activities in the aforementioned online graduate-level course. The next section details the context of the online course and the design of wiki learning activities, followed by the research questions generated in the process of design and implementation.

\section{Designing cooperative, scaffolded wiki learning activities}

\section{Course background}

The online course under investigation is part of the core curriculum in an online master's program in the area of instructional design (ID). Students in this course often have various backgrounds and experiences. Some have prior knowledge about ID from previous coursework, while others have minimal understanding. Some have related work experience as a teacher or trainer, whereas others may not have any experience or background in education.

A main focus of the course is to survey major theories that formed the foundation of the ID discipline. As such, the course has a broad coverage. The objectives of the course are for learners to: (1) explain concepts and principles of major perspectives on ID; (2) examine the influence of each perspective; (3) analyze the strengths and weaknesses of each theoretical perspective, (4) discuss implications of each perspective for ID, and (5) apply appropriate theoretical perspectives to the design of instruction for diverse audiences. The original course learning activities included quizzes, exams, reflections, online discussions, and an application project that required students to collaborate in groups to apply selected theories to design a professional development session for a target educator group.

\section{Decision to implement cooperative wiki activities}

The aforementioned background of the online course presented several challenges to the instructor. First, students had vastly different levels of knowledge and experiences. Second, the focus of the course on theories necessitates extensive readings, yet according to the instructor's experience, as well as the literature, students often do not complete assigned readings that are intended to prepare them for further coursework (Burchfield \& Sappinton, 2000). Although quizzes can provide certain measures for assessments and accountability, both readings and quizzes are still solo activities that do not offer the opportunity for students to engage with each other in the process. Online discussions, on the other hand, provide a social platform for exchange, but they are better suited for discussing certain questions than addressing a topic in a holistic manner. 
In consideration of the above factors, the instructor adopted wikis, a tool available in the course's Blackboard Learning Management System, to facilitate students' readings and promote their understanding. In light of the literature, the wiki learning activities were intended to (1) promote students' cognitive presences through a more engaged process of reading and collective knowledge building, and (2) provide a platform for social presence, whereby students from different backgrounds could benefit from seeing each other's works, thus developing a sense of class community.

Further, the wiki activities were designed to be exploratory and cooperative in nature. Students worked on a total of 10 wiki pages throughout the semester, each focusing on a key theoretical perspective in ID. Each student contributed to a portion of each wiki based on weekly readings. With the accumulation of their entries, the wikis became a collectively-built knowledge base. Complementing other assignments and activities in the course, the wiki activities provided an intermediate way to prepare students and orient them into more collaborative activities such as online discussions and the application project, which served to achieve higher-order learning outcomes. The next section details how students were scaffolded throughout the wiki activities.

\section{Scaffolding cooperative wiki activities}

To support students in completing the wiki activities, scaffolding was provided in three aspects: activity design, peer scaffolding, and expert scaffolding. Table 1 provides a summary of the scaffolding strategies.

\section{Scaffolding with activity design}

Activity design consisted of three components: pre-readings, activity guidelines, and templates. At the beginning of each week, the instructor posted to the course website assigned readings. The readings included textbook chapters, related articles, instructor's weekly video highlights of important topics, and sometimes additional multimedia

Table 1 Scaffolding Strategies to Support Wiki Learning Activities

\begin{tabular}{|c|c|}
\hline Elements & Description \\
\hline \multicolumn{2}{|l|}{ 1. Activity Design } \\
\hline Pre-readings & $\begin{array}{l}\text { Readings and multimedia materials designed to prepare students for } \\
\text { the wiki learning activities }\end{array}$ \\
\hline Guidelines & $\begin{array}{l}\text { Designed to inform students about the purposes and requirements of } \\
\text { each activity }\end{array}$ \\
\hline Template & $\begin{array}{l}\text { Designed in the form of a table to outline key aspects of a topic, and } \\
\text { to facilitate cooperative contributions }\end{array}$ \\
\hline \multicolumn{2}{|l|}{ 2. Peer Scaffolding } \\
\hline Cooperative editing & Students created wiki entries based on existing peers' entries \\
\hline $\begin{array}{l}\text { Accessing and reviewing peers' } \\
\text { works \& the final version }\end{array}$ & Students had access to peers' entries and the final version of the wikis \\
\hline \multicolumn{2}{|l|}{ 3. Expert Scaffolding } \\
\hline Instructor's feedback & $\begin{array}{l}\text { Instructor's summary of an activity and identification of possible } \\
\text { misunderstandings at the conclusion of a wiki activity }\end{array}$ \\
\hline Expert version & $\begin{array}{l}\text { In some cases, an "expert" version was provided by the instructor to } \\
\text { show how an expert would approach a wiki task }\end{array}$ \\
\hline
\end{tabular}


materials on the week's topics. The readings served to prepare students for the wiki learning activities.

Guidelines were provided for each wiki activity. The guidelines were designed to inform students the purposes and requirements of a wiki activity. Generally, the 10 activities built on weekly readings and aimed to achieve lower levels of learning outcomes in Bloom's taxonomy (i.e., understand, apply, analyze), which prepared students for subsequent higher-order learning activities. Table 2 illustrates each type of wiki activities with examples.

Instead of starting with a blank page, a template was provided on the initial page of each wiki. The template was intended to delineate key aspects of an activity based on the relevant theories in assigned readings, which also helped to facilitate students' cooperative work. An example template is depicted in Fig. 1.

\section{Peer scaffolding}

Peer scaffolding was reflected in two aspects as students worked on the wiki pages. First, students' contributions were built upon the existing entries contributed by peers. Second, students had the opportunity to access and review peers' works on the same wiki pages, as well as the final completed version as a whole-class effort. Both the peers' works and the final versions could be a source of learning and a knowledge base for reference.

\section{Expert scaffolding}

The instructor provided expert scaffolding in two ways. The first is through feedback and summary. At the end of each week, the instructor reviewed student's contributions. If a student did not contribute, the instructor would remind the student. If students showed misunderstandings, the instructor would point out in the general feedback to the class. In one case where the class showed substantial misunderstandings of an important topic, the instructor recorded an additional video to provide further clarifications. In addition to feedback, the instructor posted a summary to each wiki, highlighting key takeaways from the activity.

The second way of expert scaffolding was the provision of an expert version by the instructor. For example, after students compared four views of communications theory in a wiki activity, the instructor shared her version of comparisons, so that students could compare with their own work.

Table 2 Types of Wiki Learning Activities

\begin{tabular}{|c|c|}
\hline Types of activities & Examples \\
\hline $\begin{array}{l}\text { Facilitate } \\
\text { understanding }\end{array}$ & $\begin{array}{l}\text { - Comparison of communication models } \\
\text { - How would the behavioral learning theory answer these questions? (a list of questions } \\
\text { was provided) }\end{array}$ \\
\hline Facilitate application & $\begin{array}{l}\text { Given a teaching-learning scenario - } \\
\text { - Applying Gagne's Nine Events of Instruction } \\
\text { - How will you identify objectives \& sequence instruction? }\end{array}$ \\
\hline Facilitate analysis & $\begin{array}{l}\text { Given a video case - } \\
\text { - Analyzing elements \& implementation of constructivist learning }\end{array}$ \\
\hline
\end{tabular}




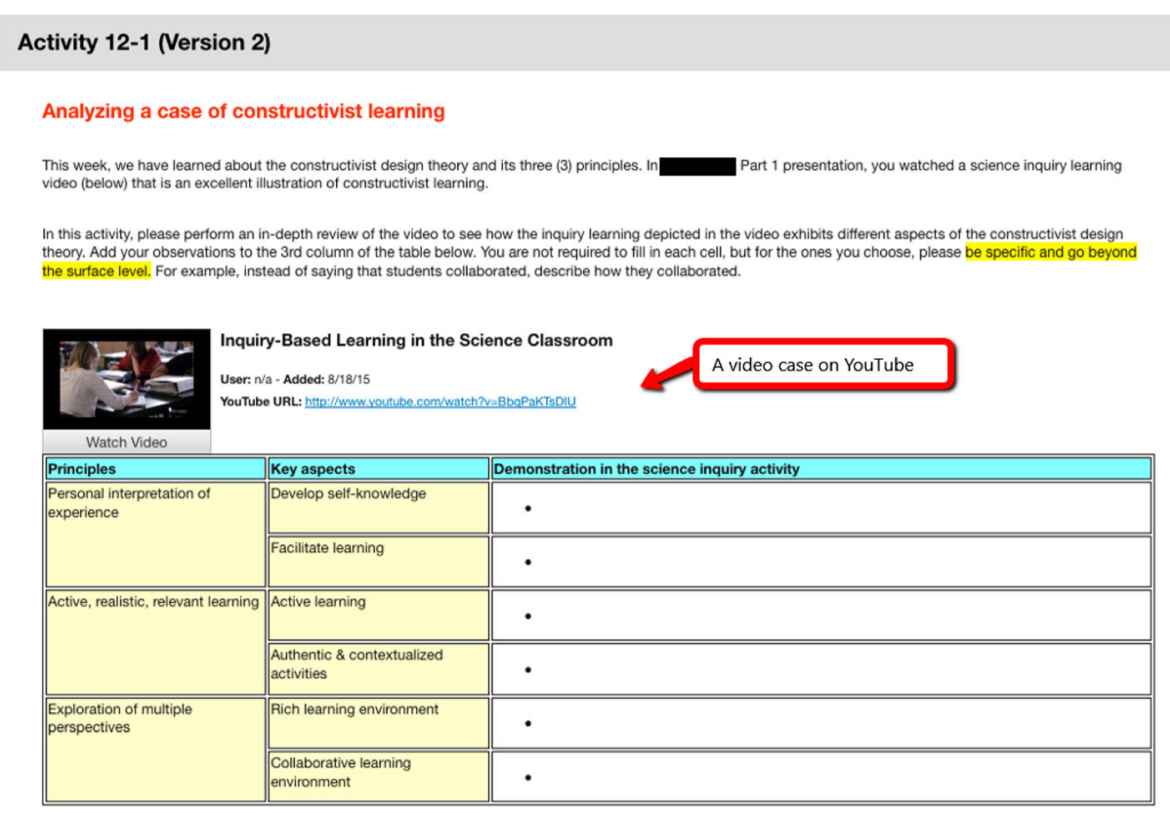

Fig. 1 A template used to scaffold cooperative wiki work in analyzing a video case of inquiry learning in science

\section{Research questions}

In the design and implementation of the wiki activities, the following research questions emerged:

1. How did students participate in the cooperative wiki learning activities?

2. Was students' participation in the wiki learning activities related to their course performance?

3. How did students perceive their learning experiences with the wiki activities, in terms of the activities' purposes, scaffolding strategies, and issues?

\section{Method}

The study was conducted in an online graduate-level class at a large university in the southeastern United States. Ten graduate students from the class participated in the study through informed consent. The study was approved by the university's Institutional Review Board, and applicable ethical guidelines were observed throughout the study.

A total of 10 wiki activities were implemented in the online course. There was no requirement regarding the length or coverage of students' contributions to each wiki, other than that they needed to show "due effort." Except for one activity which assigned each student to work on specific elements in a wiki template, students had the freedom to choose which element(s) to contribute to.

Five sets of data were collected to answer the research questions. First, Blackboard-aggregated data were collected on the number of words modified by each student across the 10 wikis. Second, Blackboard-archived modification history and the final version of each wiki were gathered. Third, students' grades were collected as their performance data. The grades were calculated by adding those of all the individual 
assignments, while excluding the grade for the application project, which was a group assignment. Fourth, students' end-of-semester reflective essays were collected. While the essay did not explicitly require students to reflect on the wiki activities, the reflections were reviewed in case wikis are mentioned. Lastly, four students volunteered to complete an open-ended questionnaire that inquired their perceptions of the wiki activities. The questions asked students to describe their perceived purposes of the wiki activities, the process they went about completing an activity, their perceptions of and experiences with the scaffolding strategies, and the issues they experienced in the process.

To answer the first research question, the number of words modified by each student was calculated. Final wiki pages and modification history, together with students' responses to the questionnaire were analyzed. Emerging patterns in students' participation were identified and refined through an iterative cycle. To answer the second question, students' calculated grades were correlated with their total numbers of modified words to identify whether there was a significant relationship. To answer the third research question, students' responses to the questionnaire were analyzed in three aspects: perceived goals of the wiki activities, perceptions of scaffolding strategies, and perceived issues. Within each aspect and sub-aspect, themes were drawn from the data. Table 3 summarizes the data sources for each research question.

\section{Results}

\section{Question 1: students' participation in wikis}

Blackboard-aggregated contribution data indicated that, overall, the 10 students modified a total of 11,902 words, averaging 1190 words per wiki $(\mathrm{SD}=480)$. There was a wide range in the students' number of modified words (330-1989). Modification history suggested that students generally showed "due effort" by having original contributions that demonstrated certain levels of understanding and application. As stated by student 3 , "the nature of the wiki assignments encouraged me to bring something new to the table."

In terms of participation, the following patterns were identified from the modification history and student reports in the questionnaire. The first is regarding the frequency of

Table 3 Data Sources for Research Questions

\begin{tabular}{ll}
\hline Research Questions & Data Sources \\
\hline $\begin{array}{ll}\text { 1. How did students participate in the cooperative } \\
\text { wiki learning activities? }\end{array}$ & $\begin{array}{l}\text { - Blackboard-aggregated participation data (number of } \\
\text { words modified by students) } \\
\text { - Blackboard-archived modification history by students } \\
\text { - Part of an open-ended questionnaire responded by } \\
\text { four volunteer students, regarding their participation in } \\
\text { the wiki activities }\end{array}$ \\
$\begin{array}{ll}\text { - The final versions of all the wikis } \\
\text { 2. Was students' participation in the wiki learning }\end{array}$ & $\begin{array}{l}\text { - Students' numbers of modified words in wikis } \\
\text { activities related to their course performance? }\end{array}$ \\
$\begin{array}{ll}\text { - Students' course grades (excluding a group-based } \\
\text { grade) }\end{array}$ \\
$\begin{array}{ll}\text { experiences with the wiki activities, in terms of the } \\
\text { activities' purposes, scaffolding strategies, and issues? }\end{array}$ & $\begin{array}{l}\text { - Part of an open-ended questionnaire responded by } \\
\text { four volunteer students, regarding their experiences } \\
\text { with the wikis }\end{array}$ \\
& $\begin{array}{l}\text { Students' end-of-semester written reflections (a course } \\
\text { assignment), in case a student reflected on the wiki } \\
\text { activities }\end{array}$ \\
\hline
\end{tabular}


participation. Most students completed their work in one or two sittings. In case of the latter, the second sitting was usually shortly after the first one. With the proximity of time between the two sittings, there were often limited new entries, from which students could potentially gain new perspectives. There was one exception, however. One student participated early in the week and made frequent entries throughout the week. Interestingly, the student also had the lowest number of modified words in the class.

The second pattern is regarding students' selection of elements to work on in completing the activities. Although students were not required to address multiple elements in a wiki template, the wiki history suggested that most students opted to work on multiple elements in all wikis. The selection of specific elements varied with the timing of contribution. In the case of being able to contribute early in a week, student 2 indicated, "I picked the part of the assignment that I found most interesting from reading the text or watching the class videos." In case of a late contribution where all the elements had been addressed by classmates, it could be a challenge, as reported by students 1 and 2. Student 2 indicated that she would look for areas that were "underdeveloped," and at times, she enjoyed the challenge of taking "a fair dose of creativity and insight to add something meaningful to the discussion."

The third pattern is regarding the extent to which students referred to peers' contributions in writing their own. Modification history showed that most entries did not make explicit references to peers' entries. However, there were a few cases where students either expressed agreement with a peer's entry, or elaborated or built on peers' ideas. Not surprisingly, the final wiki pages were more of a compilation of discrete, occasionally repetitive ideas than a coherent list with clear logical connections among ideas.

\section{Question 2: relationship between wiki participation and course performance}

Students' course grades were correlated with their numbers of modified words in wikis, which served as an indicator of participation. The correlation was not significant, $r$ $=.12, p=.74$. The result suggested that the amount of contributions to wikis was not related to students' performance in the course.

\section{Question 3: wiki learning experiences Perceived purposes of wiki activities}

In general, students' perceived purposes of wiki activities were aligned with the design intentions. They believed that the activities achieved three purposes. First, the cooperative activities served as a motivator. As elaborated by student 3, the activities "helped motivate me ... My submission was part of a larger whole that other students were creating. This added encouragement pushed me to search the material on a deeper level so that I could provide valuable material to the wikis." Second, the activities developed a sense of interaction and class community in the online course. Student 3 observed that the activities "closely simulated a face-to-face class experience through a fairly casual class interaction," and "presented some of the interaction that you find in a group project." As multiple students worked towards a common goal throughout the semester (student 2), the activities "helped build a feeling of cohesiveness between the classmates" (student 3). 
Third, the activities helped students to establish a comprehensive understanding of the target topics in the wikis. Student 2 indicated that the contributions by all $10 \mathrm{stu}$ dents to every wiki made it "more likely ... all of the important topics will get covered." As a result, the activities allowed them to "learn from each other's strengths" (student 4) and helped them to consider multiple perspectives that they may not have otherwise considered (student 3). As commented by another student in his reflection, the class had "some very intelligent students," whose "depth of knowledge and understanding was really unbelievable."

\section{Perceptions of scaffolding strategies}

Students' perceptions of the three scaffolding strategies (activity design, peer scaffolding, expert scaffolding) are reported below.

Strategy 1: activity design Regarding the three elements of activity design (prereadings, guidelines, and templates), students believed that the first element, prereadings, prepared them for the wiki activities. In particular, student 4 commented that "the pre-activities ... correlated with the directions well in order to complete the wiki." Before starting the wiki activities, students would make sure to review the pre-reading materials, which helped to ensure the accuracy of their responses.

Regarding the second element of activity design, guidelines, students' perceptions fell into three aspects. First, the rationale part of the guidelines "acted as additional motivators," because "Nobody likes busy work; understanding the value of an educational experience increases caring about it" (student 2). Second, student 3 wrote that the guidelines were "straightforward and concise in a way that guided students toward the right information, but they were also general enough to encourage educational discovery." Third, it appears that students preferred some activities more than others. In particular, student 1 felt that the "hypothetical scenarios" in some activities helped him to "feel more connected to the material." Student 2 liked more "open-ended ill-defined" activities. She took one of the wikis, Applying Gagne's Nine Events of Instruction, as an example, and stated:

This worked particularly well as a wiki assignment as we were all building on each other's ideas, while contributing our unique points of views. This allowed for creativity in forms of fluency (multiple ideas), flexibility (multiple categories of ideas), elaboration (some people's contributions were quite detail-rich), and originality (seeing the contributions of others one had to come up with something new).

This resulted in one of heavier-populated assignments, I believe. It was fun!

Regarding the third and last element of activity design, templates, students appreciated their "familiar 'fill in the blank' appearance," while providing "enough room for learner interpretation" (student 3). Further, students stated that the templates "compartmentalized all of the particular sections that needed to be answered" (student 1), which "ensured that all the parts were addressed" (student 2). More importantly, student 1 believed that the templates "provided a much easier method of divvying up the assignment between ourselves." 
Strategy 2: peer scaffolding In getting ready to contribute their own entries, students reported routinely reviewing peers' entries to achieve three main purposes with incremental levels of processing. The first purpose was to identify "what could be added" (student 1) or to "assure I didn't 'double up' on information" (student 2). Achieving this purpose required relatively low effort, from looking for a bullet point no one had contributed yet, to skimming the entries and quickly identifying a point to contribute. The second purpose was to use peers' works to gauge their own levels of contribution, as elaborated by student 1 , "I read others' posts to figure out the expectations, particularly the level of how in-depth I would need to go when fulfilling my part ... so that I would not seem like I wasn't adequately contributing to the team." Compared with the first two purposes, the third one involved more learning from peers, which was to use peers' works to assure or inform one's own contributions. For example, student 4 always read classmates' posts even if she was sure of her own contributions. She believed that peers' posts either helped to assure her own responses, or "guided me into completing more research/seeking further instruction so that I could understand the learning activity to the full extent." Similarly, student 2 found reviewing peer's contributions as "a way to check my knowledge on the subject and clarify potential misunderstandings." The highest level of processing afforded by the peer scaffolding was observed in student 4. At times when she was unsure how to approach an activity, she would wait for classmates' posts to get ideas, while at other times, peers' posts would prompt her to go back and "edit/change/adapt (her own) response or ... form a better understanding of the skill/ learning activity."

Although all four students read peers' entries before writing their own, their practices varied in reviewing peer entries or the final versions of the wikis after contributing their own entries. For example, student 2 "usually didn't have the time" to review posts later than hers. Comparatively, student 1 would revisit a wiki just to "see if all of the boxes were full," but he "wouldn't necessarily read every single answer there every time." His focus was more on completing his own portion than learning from peers, about which he indicated, "I really learned a lot about the particular sections where I contributed, but overall, I didn't take the time to understand the entire assignment. Maybe it was due to my laziness or perhaps I was just too busy to read everyone's contributions." In the same vein, he would not revisit a wiki once the activity was completed, feeling it as "a waste of time," unless a later assignment required him to do so. Students 3 and 4, on the other hand, not only routinely revisited the wikis to review newer entries, but also tried to learn from the experience. Student 3 described the cooperative editing as a curious process "similar to watching a puzzle being slowly assembled," which "at the end ... come together to provide a very insightful look into the discussed topic." For completed wikis, he found them to be "a valuable study asset" that he could revisit to seek clarifications when he was confused or uncertain about a concept. Student 4 felt that the wikis helped her to "understand later (course learning) activities that built upon each other." She particularly appreciated the "forming (of) a collection of knowledge that provided different perspectives of instructional systems design." She further commented, "Different classmates worked in different sectors of education/instructional design. It was very enlightening to read how someone who works in higher ed vs. K-12 vs. the private sector views the learning activity differently." 
Strategy 3: expert scaffolding Regarding the instructor's summary, feedback, and expert versions, all the students found them to be helpful. The expert scaffolding appeared to be helpful in four aspects. The first was to validate students' contributions. For example, student 2 reviewed the feedback and summaries to "make sure I understood the material and addressed the questions correctly." The second aspect was to correct any misunderstandings. Student 3 wrote, "The information within the wiki was created by learners who may or may not fully understand the concept or scenario which leaves the door open to inaccuracies ... students could rely upon (the instructor's feedback and summaries) as being accurate." The third benefit of expert scaffolding was to fill in any knowledge gaps shown in the students' works. Student 4 felt that the instructor's information often had "extra tidbits" that helped her to develop the full picture when the class did not show full understanding in their contributions. Lastly, beyond the scope of the wikis, the instructor's feedback and summaries were used as exam refreshers by student 2 .

\section{Perceived issues}

In their responses to the questionnaire, students identified four general issues experienced in working on the cooperative wiki activities. The first issue had to do students' roles when they saw clear mistakes or misunderstandings in peers' entries. Student 2 elaborated her experience, "Occasionally, someone would post something blatantly incorrect. I didn't really know what to do in such instance: was I supposed to address it? Was I free to delete it? It would be helpful for me to have additional guidance regarding incorrect information." The second issue happened in the first wiki activity when some students were unclear how wikis work and deleted peers' contributions, which they mistakenly thought were only the instructor's examples for them to emulate.

While the first two issues mainly had to do with the guidelines provided to the students, the next two issues were more related to the wiki technology. Student 2 felt that an easier and quicker way to know the identities of authors would help her to better relate to peers' works: "I would find it awkward to say: 'to whoever stated that such and such on the wiki: I partially agree, because ... "' For a different purpose, student 1 would like a quick way to identify who has or has not contributed yet to a wiki. He stated,

Many times, I would be incredibly busy during the main part of the week, leaving only the latter half of the week/weekend to contribute to the assignments. Whenever I would $\log$ in to see what I can add to our wiki, almost all of it would be done already... If it were possible to keep a running tally of who has contributed, then the rest of the team would know that there might be people left who haven't had a chance to help. That way a small handful of people don't complete the entire assignment, leaving everyone else to get a bad grade for not being able to participate.

As shown in his statement, student 1 was concerned that late contributors might have difficulty finding where to contribute, and hoped that early contributors would leave room for others. 


\section{Discussion}

Setting out to promote the community of inquiry (Garrison et al., 2000) in a graduate-level online class, this study implemented wikis as a pedagogical tool to support learning activities that worked holistically with other course activities to promote students' cognitive and social presences. Informed by the literature, the instructor designed cooperative, scaffolded wiki learning activities (Ge et al., 2012; Hadjerrouit, 2014), and investigated emerging research questions.

\section{Effectiveness of cooperative, scaffolded wiki activities}

While wikis have been regarded a tool that affords collaborative work, research found that students' levels of collaboration were often low in wikis (Cho \& Lim, 2017; Lin \& Kelsey, 2009). Accordingly, this study investigated an alternative use of wikis to support cooperative learning experiences. The findings suggested that cooperative wiki activities could be an effective part of an online course, especially for those that have an extensive theoretical focus and a diverse student body. As shown in the results, students had reasonable levels of participation. Although the quantity of contribution by the number of words did not correlate with students' performance in the class, the findings did show benefits of the activities in promoting students' cognitive and social presences in the class.

By its cooperative nature, the wikis presented a challenge for each student to bring something new to the collective work. As the findings suggested, the challenge and the mindset of contributing part of a bigger whole motivated students to dig deeper into the course content. Further, the fact that multiple students contributed uniquely to a general topic increased the likelihood that different aspects of the topic were adequately addressed. What's more, the cooperative activities took advantage of students' diverse backgrounds, which enabled them to learn from each other's strengths and experiences. Overall, the activities led to the compilation of comprehensive knowledge bases on important topics, which according to the findings, helped to prepare later course activities.

In addition to promoting cognitive presences, the activities also helped to promote students' social presences, because they had to work together as a class on the wiki activities regularly throughout the semester. The findings suggested that students got to know each other's experiences and background at a heightened level. The experiences, while being cooperative, helped to prepare students for the collaborative project later in the semester.

\section{Implications for designing and facilitating online learning}

The study offers implications for promoting communities of inquiry in online learning. To increase teaching presence, online instructors and designers can utilize pedagogical expertise, research-informed best practices, together with appropriate learning technologies to design meaningful learning activities for specific learners, content, and learning contexts. When the activities engage learners in purposeful and cooperative inquiries to build collective knowledge bases, and when their inquiries are structured, challenged, and supported with 
appropriate scaffoldings, cognitive and social presences are heightened in the community.

Several tool-specific strategies (Cho \& Lim, 2017) can be drawn from the study regarding cooperative wiki learning activities.

1. Given the nature of the activities, they would better serve lower-order learning outcomes, while complementing other higher-order, collaborative learning activities within a course.

2. Pre-readings should be designed to correlate well with the wiki learning activities.

3. The activity guidelines should address the rationale for an activity, so that students develop a clear purpose.

4. Try to design wiki activities that are scenario-based and open-ended, so that students have a better opportunity to apply what they read.

5. Use a template to structure a wiki task and to facilitate students' division of tasks.

6. Expert feedback, summary, and examples are helpful, since students rely on them as accurate sources.

7. Provide practice opportunities to help students become familiar with wikis as a tool.

The issues emerged from the findings require further consideration in designing effective learning experiences. For instance, the guidelines for wiki activities need to consider the frequency and timing of students' participation. Specifically, should the guidelines require spaced participation so that everyone can benefit from seeing others' contributions? Since contributions can get harder over time, should the guidelines define a scope for students' contributions, or leave it as a challenge for late contributors to tackle? Further, cooperative wiki activities need to provide clear guidelines regarding what to do when peers' entries show clear misunderstandings. Also, mechanisms or strategies could be devised for students to refer to each other's works more easily at a more personal level. The above questions need further rounds of design, implementation, and investigation.

\section{Implications for research}

The study yields implications for further research in two areas. The first is individual students' differences in handling cooperative learning activities, and the factors behind the differences. To illustrate, students 1 and 2 both faced the challenge of finding a way to contribute later in the week, yet student 1 would like classmates to leave room for later contributors, whereas student 2 enjoyed the challenge. Understanding the differences and the underlying factors could better inform the design of the activities for an increasingly diverse online student body.

The study also has implications for research on scaffolding student learning. In this study, not all the scaffolding strategies achieved their design intentions, especially peer scaffolding. By design, the wikis were intended for students to build on each other's works, use the compiled wikis as knowledge bases, and acquire knowledge from the peer learning experience. In actual implementation, some students did take advantage of peer scaffolding by carefully reviewing peers' posts to find areas to contribute, 
revising own posts based on new perspectives gained from peers, and referring back to the wikis as a learning resource. On the other hand, there were students who focused on making their own contributions, while using peers' works only as a gauge for effort. Further, they did not return to the wikis after posting their own. In these cases, the peer scaffolding was not used as intended, and peer learning was minimal. While the scaffolding literature provided rich frameworks to scaffold learning in various settings (e.g., Belland et al., 2008; Ge \& Land, 2004; Quintana et al., 2004), we know much less about how students actually use scaffolds. This study pointed out potential issues in learners' use of scaffolding, which warrants further research.

\section{Conclusion}

This study demonstrated a teacher/researcher's effort in investigating and improving online learning in a local context. By examining and applying research-based best practices to promote learning for specific learners, subject areas, and contexts, and by experimenting with emerging technologies, online instructors are in a unique position to engage in design experiments (Brown \& Campione, 1996) and reflective practices that can contribute to the theories and practice of online learning. This study has several limitations. First, the study investigated only a small sample of students which may not have yielded sufficient findings. Second, students' cognitive and social presences could be measured to provide an additional lens for the findings. Third, with more reliable learning management systems, more indicators of students' engagement, such as time spent on wikis, could be captured for a more comprehensive understanding.

Acknowledgements

Not applicable.

Funding

Not applicable.

Availability of data and materials

The datasets generated and/or analysed during the current study are not publicly available due to the rules and guidelines of the review board at the author's institution, but are available from the author on reasonable request.

Authors' contributions

The author read and approved the final manuscript.

Competing interests

The author does not have any competing interests in the manuscript.

\section{Publisher's Note}

Springer Nature remains neutral with regard to jurisdictional claims in published maps and institutional affiliations.

Received: 15 January 2019 Accepted: 20 March 2019

Published online: 25 April 2019

\section{References}

Ahlholm, M., Grunthal, S., \& Harjunen, E. (2017). What does wiki reveal about the knowledge processing strategies of school pupils? Seventh-graders as users of wiki and processors of knowledge in a collaborative writing project. Scandinavian Journal of Educational Research, 61(4), 448-464.

Akyol, Z., \& Garrison, D. R. (2011). Understanding cognitive presence in an online and blended community of inquiry: Assessing outcomes and processes for deep approaches to learning. British Journal of Educational Technology, 42(2), 233250. https://doi.org/10.1111/j.1467-8535.2009.01029.x.

Arbaugh, J. B., Cleveland-Innes, M., Diaz, S. R., Garrison, D. R., Ice, P., Richardson, J. C., \& Swan, K. P. (2008). Developing a community of inquiry instrument: Testing a measure of the Community of Inquiry framework using a multi-institutional sample. Internet and Higher Education, 11(3-4), 133-136.

Belland, B., Glazewski, K., \& Richardson, J. (2008). A scaffolding framework to support the construction of evidence-based arguments among middle school students. Educational Technology Research and Development, 56(4), 401-422. https://doi. org/10.1007/s11423-007-9074-1. 
Belland, B. R., Kim, C., \& Hannafin, M. J. (2013). A framework for designing scaffolds that improve motivation and cognition. Educational Psychologist, 48(4), 243-270. https://doi.org/10.1080/00461520.2013.838920.

Breslow, L., Pritchard, D. E., DeBoer, J., Stump, G. S., Ho, A. D., \& Seaton, D. T. (2013). Studying learning in the worldwide classroom research into edX's first MOOC. Research \& Practice in Assessment, 8, 13-25.

Brown, A. L., \& Campione, J. C. (1996). Psychological theory and the design of innovative learning environments: On procedures, principles, and systems. In L. Schauble, \& R. Glaser (Eds.), Innovations in learning: New environments for education. Mahwah: Erlbaum.

Burchfield, C. M., \& Sappinton, J. (2000). Compliance with required reading assignments. Teaching of Psychology, 27(1), 58-60

Chao, Y. C. J., \& Lo, H. C. (2011). Students' perceptions of wiki-based collaborative writing for learners of English as a foreign language. Interactive Learning Environments, 19(4), 395-411. https://doi.org/10.1080/10494820903298662.

Cho, M., \& Lim, S. (2017). Using regulation activities to improve undergraduate collaborative writing on wikis. Innovations in Education and Teaching International, 54(1), 53-61.

De Wever, B., Hamalaninen, R., Voet, M., \& Gielen, M. (2015). A wiki task for first-year university students: The effect of scripting students' collaboration. Internet and Higher Education, 25, 37-44.

Filius, R. M., de Kleijn, R. A. M., Uijl, S. G., Prins, F. J., van Rijen, H. V. M., \& Grobbee, D. E. (2018). Strengthening dialogic peer feedback aiming for deep learning in SPOCs. Computers \& Education, 125, 86-100.

Garrison, D. R. (2017). E-learning in the $21^{\text {st }}$ century: A community of Inquiry framework for research and practice, (3rd ed., ). New York: Routledge.

Garrison, D. R., Anderson, T., \& Archer, W. (2000). Critical inquiry in a text-based environment: Computer conferencing in higher education. The Internet and Higher Education, 2(2-3), 87-105. https://doi.org/10.1016/S1096-7516(00)00016-6.

Garrison, D. R., Cleveland-Innes, M., \& Fung, T. S. (2010). Exploring causal relationships among teaching, cognitive and social presence: Student perceptions of the community of inquiry framework. Internet and Higher Education, 13, 31-36.

Ge, X., \& Land, S. (2004). A conceptual framework for scaffolding ill-structured problem solving processes using question prompts and peer interactions. Educational Technology Research and Development, 52(2), 5-22. https://doi.org/10.1007/BF02504836.

Ge, X., Law, V., \& Huang, K. (2012). Diagnosis, supporting, and fading: A scaffolding design framework for adaptive elearning systems. In H. Wang (Ed.), Interactivity in E-Learning: Case Studies and. Frameworks. Hershey, PA: IGI Global. (pp. 116-142).

Greenhow, C., Robelia, B., \& Hughes, J. (2009). Learning, teaching, and scholarship in a digital age. Educational Researcher, 38(4), 246-259. https://doi.org/10.3102/0013189X09336671.

Hadjerrouit, S. (2014). Wiki as a collaborative writing tool in teacher education: Evaluation and suggestions for effective use. Computers in Human Behavior, 32, 301-312.

Hambacher, E., Ginn, K., \& Slater, K. (2018). From serial monologue to deep dialogue: Designing online discussions to facilitate student learning in teacher education courses. Actions in Higher Education, 40(3), 239-252. https:/doi.org/10.1080/ 01626620.2018 .1486753$.

Hattingh, L. H., Robinson, D., \& Kelly, A. (2018). Evaluation of a simulation-based hospital pharmacy training package for pharmacy students. International Journal of Educational Technology in Higher Education, 15(39). https://doi.org/10.1186/ s41239-018-0120-3.

Hew, K. F., \& Cheung, W. S. (2013). Use of web 2.0 technologies in K-12 and higher education: The search for evidence-based practice. Educational Research Review, 9, 47-64

Hsu, Y., Ching, Y., \& Grabowski, B. L. (2014). Web 2.0 applications and practices for learning through collaboration. In J. M. Spector, M. D. Merrill, J. Elen, \& M. J. Bishop (Eds.), Handbook of research on educational communications and technology, (pp. 747-758). New York: Springer New York.

Huang, K., Law, V., \& Lee, S. J. (2018). The role of learners' epistemic beliefs in an online community of inquiry. British Journal of Educational Technology. https://doi.org/10.1111/bjet.12684.

Huang, K., Lee, S. J., \& Dugan, A. (2016). Leveraging teaching presence in online courses: Strategies, technology, and student perspectives. In S. D'Agustino (Ed.), Creating teaching immediacy in online learning environments. Hershey, PA: IGI Global.

Islam, T. A., Flint, J., Jaecks, P., \& Cap, C. H. (2017). A proficient and versatile online student-teacher collaboration platform for large classroom lectures. International Journal of Educational Technology in Higher Education, 14(29). https://doi.org/10. 1186/s41239-017-0067-9.

Jung, I., \& Suzuki, Y. (2015). Scaffolding strategies for wiki-based collaboration: Action research in a multicultural Japanese language program. British Journal of Educational Technology, 46(4), 829-838.

Kim, M. (2012). Revisiting cognitive tools: Shifting the focus to tools-in-use. Educational Technology, 52(4), 14-24.

Lau, W. W. F., Lui, V., \& Chu, S. K. W. (2017). The use of wikis in a science inquiry-based project in a primary school. Educational Technology Research and Development, 65(3), 533-553.

Lin, H., \& Kelsey, K. D. (2009). Building a networked environment in wikis: The evolving phases of collaborative learning in a wikibook project. Journal of Educational Computing Research, 40(2), 145-169. https://doi.org/10.2190/EC.40.2.a.

Morrison, G. R., Ross, S. M., Morrison, J. R., \& Kalman, H. K. (2019). Designing effective instruction, (8th ed., ). Hoboken: Wiley.

Quintana, C., Reiser, B. J., Davis, E. A., Krajcik, J., Fretz, E., Duncan, R. G., et al. (2004). A scaffolding design framework for software to support science inquiry. Journal of the Learning Sciences, 13(3), 337-386.

Reich, J., Murnane, R., \& Willett, J. (2012). The state of wiki usage in U.S. K-12 schools: Leveraging web 2.0 data warehouses to assess quality and equity in online learning environments. Educational Researcher, 41(1), 7-15.

Sadaf, A., \& Olesova, L. (2017). Enhancing cognitive presence in online case discussions with questions based on the practical inquiry model. The American Journal of Distance Education, 31(1), 56-59.

Saye, J. W., \& Brush, T. (2002). Scaffolding critical reasoning about history and social issues in multimedia-supported learning environments. Educational Technology Research and Development, 50(3), 77-96.

Sharp, L. A., \& Whaley, B. (2018). Wikis as online collaborative learning experiences: "A different kind of brainstorming.". Adult Learning, 29(3), 83-93.

Simonson, M., Smaldino, S., \& Zvacek, S. (2015). Teaching and learning at a distance: Foundations of distance education, (6th ed., ). Charlotte: Information Age. 
Stoddart, A., Chan, J. Y., \& Liu, G. (2016). Enhancing successful outcomes of wiki-based collaborative writing: A state-of-the-art review of facilitation frameworks. Interactive Learning Environments, 24(1), 142-157.

Vaughan, N. D., Cleveland-Innes, M., \& Garrison, R. D. (2013). Teaching in blended learning environments: Creating and sustaining communities of inquiry. Edmonton: Athabasca University Press.

Wood, D., Bruner, J. S., \& Ross, G. (1976). The role of tutoring in problem solving. Journal of Child Psychology and Psychiatry and Allied Disciplines, 17(2), 89-100. https://doi.org/10.1111/j.1469-7610.1976.tb00381.x.

Submit your manuscript to a SpringerOpen ${ }^{\circ}$ journal and benefit from:

- Convenient online submission

- Rigorous peer review

- Open access: articles freely available online

- High visibility within the field

- Retaining the copyright to your article

Submit your next manuscript at $\boldsymbol{\nabla}$ springeropen.com 